\title{
Article
}

\section{Critical Care in SARS-CoV-2 Infected Pregnant Women: A Prospective Multicenter Study}

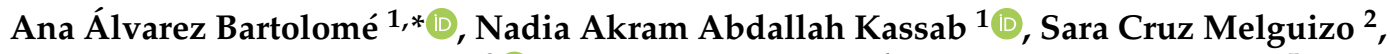 \\ María Luisa de la Cruz Conty ${ }^{3}$ D , Laura Forcen Acebal ${ }^{4}$, Alejandra Abascal Saiz ${ }^{5}$, Pilar Pintado Recarte ${ }^{6}$, \\ Alicia Martinez Varea ${ }^{7}$ D, Lucas Cerrillos Gonzalez ${ }^{8}$, Javier García Fernández ${ }^{9}$ and Oscar Martínez Pérez ${ }^{10} \mathbb{D}$
}

check for updates

Citation: Álvarez Bartolomé, A.; Abdallah Kassab, N.A.; Cruz

Melguizo, S.; de la Cruz Conty, M.L.; Forcen Acebal, L.; Abascal Saiz, A.; Pintado Recarte, P.; Martinez Varea A.; Cerrillos Gonzalez, L.; García Fernández, J.; et al. Critical Care in SARS-CoV-2 Infected Pregnant Women: A Prospective Multicenter Study. Biomedicines 2022, 10, 475. https:/ /

doi.org/10.3390/biomedicines10020475

Academic Editor: Alessandro Russo

Received: 13 December 2021

Accepted: 15 February 2022

Published: 17 February 2022

Publisher's Note: MDPI stays neutral with regard to jurisdictional claims in published maps and institutional affiliations.

Copyright: (C) 2022 by the authors. Licensee MDPI, Basel, Switzerland. This article is an open access article distributed under the terms and conditions of the Creative Commons Attribution (CC BY) license (https:// creativecommons.org/licenses/by/ $4.0 /)$.
1 Department of Anesthesia \& Critical Care, Puerta de Hierro University Hospital of Majadahonda, 28222 Madrid, Spain; nadiaabdallah90@gmail.com

2 Department of Gynecology and Obstetrics, Puerta de Hierro University Hospital of Majadahonda, 28222 Madrid, Spain; saracruz.gine@yahoo.es

3 Fundación de Investigación Biomédica, Puerta de Hierro University Hospital of Majadahonda, 28222 Madrid, Spain; farmcruz@gmail.com

4 Department of Gynecology and Obstetrics, University Hospital 12 de Octubre, 28041 Madrid, Spain; lauratrona@gmail.com

5 Department of Gynecology and Obstetrics, La Paz University Hospital, 28046 Madrid, Spain; alejandra_as@hotmail.com

6 Department of Gynecology and Obstetrics, Gregorio Marañón University Hospital, 28007 Madrid, Spain; ppintadorec@yahoo.es

7 Department of Gynecology and Obstetrics, La Fe University and Polytechnic Hospital, 46026 Valencia, Spain; martinez.alicia.v@gmail.com

8 Department of Gynecology and Obstetrics, Virgen del Rocío University Hospital, 41013 Sevilla, Spain; lcerrillog@sego.es

9 Chairman of Anesthesia \& Critical Care Department, Puerta de Hierro University Hospital of Majadahonda, 28222 Madrid, Spain; ventilacionanestesia@gmail.com

10 Maternal-Fetal Medicine Unit, Department of Gynecology and Obstetrics, Puerta de Hierro University Hospital of Majadahonda, 28222 Madrid, Spain; oscarmartinezgine@gmail.com

* Correspondence: anaalvarezbartolome@gmail.com

Abstract: Evidence suggests that pregnant women are at a higher risk of complications compared to the general population when infected with severe acute respiratory syndrome coronavirus 2 (SARS-CoV-2) and the reasons that lead them to need intensive care are not clear. This is a prospective multicenter study of SARS-CoV-2 positive pregnant women, registered by the Spanish Obstetric Emergency Group, with the objective to define the characteristics of the mothers who were admitted to the Intensive Care Unit (ICU) and to investigate the causes and risk factors for ICU admission. A total of 1347 infected pregnant women were registered and analyzed, of whom, 35 (2.6\%) were admitted to the ICU. No differences in maternal characteristics or comorbidities were observed between ICU and non-ICU patients, except for in vitro fertilization and multiple pregnancies. The main causes of admission to the ICU were non-obstetric causes (worsening of the maternal condition and respiratory failure due to SARS-CoV-2 pneumonia, 40\%) and a combination of coronavirus disease 2019 (COVID-19) symptoms and obstetrical complications (31.4\%). The multivariable logistic analysis confirmed a higher risk of ICU admission when pre-eclampsia or hemorrhagic events coexist with pneumonia. The incidence of thromboembolic events and disseminated intravascular coagulation were also significantly higher among patients admitted to the ICU. Therefore, surveillance and rapid intervention should be intensified in SARS-CoV-2 infected pregnant women with the mentioned risk factors and complications. Emphasis should always be placed on anticoagulant therapy in these patients due to the increased thromboembolic risk, C-section surgery and immobilization in the ICU.

Keywords: coronavirus disease 2019 (COVID-19); severe acute respiratory syndrome coronavirus 2 (SARS-CoV-2); pneumonia; pregnancy; intensive care 


\section{Introduction}

Severe acute respiratory syndrome due to coronavirus 2 (SARS-CoV-2) was declared as a pandemic by the World Health Organization (WHO) in March 2020 and has caused more than 164 million infections worldwide and approximately 3.4 million deaths, becoming a global health emergency [1].

There has been no data to confirm that pregnant women may have a greater predisposition to infection; however, evidence suggests that SARS-CoV-2 infected pregnant women are at higher risk of hospitalization, admission to Intensive Care Unit (ICU), invasive mechanical ventilation (IMV) and extracorporeal membrane oxygenation (ECMO) therapy compared to the general population [2].

Due to the physiological changes that occur during pregnancy, women are more vulnerable to respiratory infections and associated complications, with respiratory failure being a common cause of ICU admission [3], as the increased oxygen consumption and the decreased functional residual pulmonary capacity rapidly cause hypoxemia in case of respiratory failure [3].

Although most of the coronavirus disease 2019 (COVID-19) cases in pregnant women are mild-moderate $(88.5 \%)$, some women develop severe disease requiring oxygen therapy $(9.8 \%)$, and up to $1.6 \%$ develop critical illness [4]. Compared to non-infected pregnant women, a higher incidence of preterm delivery, cesarean section, pre-eclampsia and other morbidities have been observed in SARS-CoV-2 infected pregnancies [4].

There also seems to be an increased risk of ICU admission compared to non-pregnant women of reproductive age [5,6], but the main causes of ICU admission are unknown, as well as the maternal and fetal complications and the evolution of these patients.

The objective of the present study was to describe the characteristics of SARS-CoV-2 infected pregnant women admitted to the ICU and to investigate the causes and risk factors for ICU admission and whether obstetric pathology and type of delivery are relevant.

\section{Materials and Methods}

This is a prospective multicenter study of consecutive cases of SARS-CoV-2 infection in a cohort of pregnant women registered by the Spanish Obstetric Emergency Group in 78 hospitals [7].

A specific database was designed to record information regarding SARS-CoV-2 infection in pregnancy; the encoded data were entered by the principal researcher of each center during the enrolment period, which occurred at the time of the SARS-CoV-2 test during pregnancy and until 6 weeks after birth. We developed an analysis plan using recommended contemporary methods and followed existing guidelines for reporting our results (Supplementary Materials Table S2) [8].

We included all SARS-CoV-2 infected obstetric patients between 26 February and 5 November 2020 by testing suspicious cases admitted to the hospital due to compatible COVID-19 symptoms and by universal screening for SARS-CoV-2 infection, which was performed on all pregnant women on admission to the delivery ward (starting on 1 April 2020). SARS-CoV-2 infection was diagnosed by double-sample positive polymerase chain reaction (PCR) from nasopharyngeal swabs. All identified cases were included in the study, regardless of clinical signs and symptoms. Then, the infected patients were divided into two groups based on whether or not they required admission to intensive care units.

\subsection{Ethics}

All procedures were approved by the Drug Research and Clinical Research Ethics Committee of Puerta de Hierro University Hospital, Madrid, Spain, (Chairperson Prof. C. Avendaño Sola) on 23 March 2020 (protocol registration number, 55/20). Each collaborating center subsequently obtained protocol approval locally (ethics committees of the participant hospitals listed in the Supplementary Materials Table S1). The registry protocol is available on ClinicalTrials.gov (accessed on 1 November 2021), identifier: NCT04558996. Upon recruitment, mothers consented to participate in the study by either signing a document 
when possible, or by giving permission verbally, which was recorded in the patient's chart in the electronic clinical recording system. Ethics committees approved the possibility of verbal consent during the first three months of the pandemic, given the contagiousness of the disease and the lack of personal protection equipment. Afterward, written consent (using a patient consent form) was collected from every patient who had previously given permission verbally.

\subsection{Study Information}

Information regarding the demographic characteristics, comorbidities and current obstetric history were extracted from the clinical and verbal history of the patient. Age and ethnicity were categorized following the classification used by the CDC (Centers for Disease Control and Prevention) [6], while definitions of obstetric conditions followed international criteria [9]. For perinatal events, we recorded gestational age at delivery, the type of delivery, the type of anesthesia if required, preterm deliveries (below 37 weeks), obstetrical complications (pre-eclampsia, hemorrhagic and thromboembolic events), stillbirth, the need for invasive ventilation and/or transfusion and maternal mortality. Neonatal data, which were recorded until 14 days postpartum, included umbilical artery $\mathrm{pH}$, the need for admission in the Neonatal Intensive Care Unit and neonatal mortality.

\subsection{Data Analysis}

For descriptive data, absolute and relative frequencies were used in the case of categorical variables and medians and interquartile ranges (IQR) in the case of quantitative variables. The possible association of maternal characteristics and perinatal events with ICU admission of patients were analyzed using the Pearson's Chi-square test or Fisher's exact test for categorical variables and the Mann-Whitney $U$ test for quantitative variables (after checking the absence of normality of the data using the Kolmogorov-Smirnov test). Statistical tests were two-sided and were performed with SPSS V.20 (IBM Inc., Chicago, IL, USA); statistically significant associations were considered to exist when the $p$-value was less than 0.05 .

To check the association of the perinatal complications that were statistically significant in the univariable analysis with ICU admission, the influence of confounding factors (and interactions) was controlled for with multivariable logistic regression modeling to derive adjusted odds ratios (aOR) with 95\% confidence intervals (95\% CI). Models were built for each perinatal complication separately, incorporating a range of variables and/or interactions after verifying the statistical association of potential confounding factors with ICU admission and the perinatal complication of interest (excluding intermediate variables of the causal chain) and in accordance with the ten-to-one event per variable rule to avoid model overfitting [10]. Modeling was conducted after excluding pregnancies with missing data and using a bootstrapping procedure for resampling cases (with a number of bootstrap samples equal to 999). Once the maximum multivariable logistic regression model was constructed, and to achieve the final estimated model, a confounder remained in the model if the coefficient for the perinatal complication changed by more than ten percent when the potential confounder was removed. Regression analyses were performed with the lme4 package in R, version 3.4 (RCore Team, 2017) [11]. A complete list of the final set of covariates is provided with each model in the results section.

\section{Results}

During the study period, 1347 infected pregnant women were registered and analyzed in the 78 hospitals; 35 (2.6\%) were admitted to the ICU, and $1312(97.4 \%)$ did not require intensive care (Figure 1). Of pregnant women admitted to the ICU, 91.4\% were in the third trimester of gestation and only $8.6 \%$ in their second trimester; $80 \%$ of patients were admitted to the ICU after giving birth. 


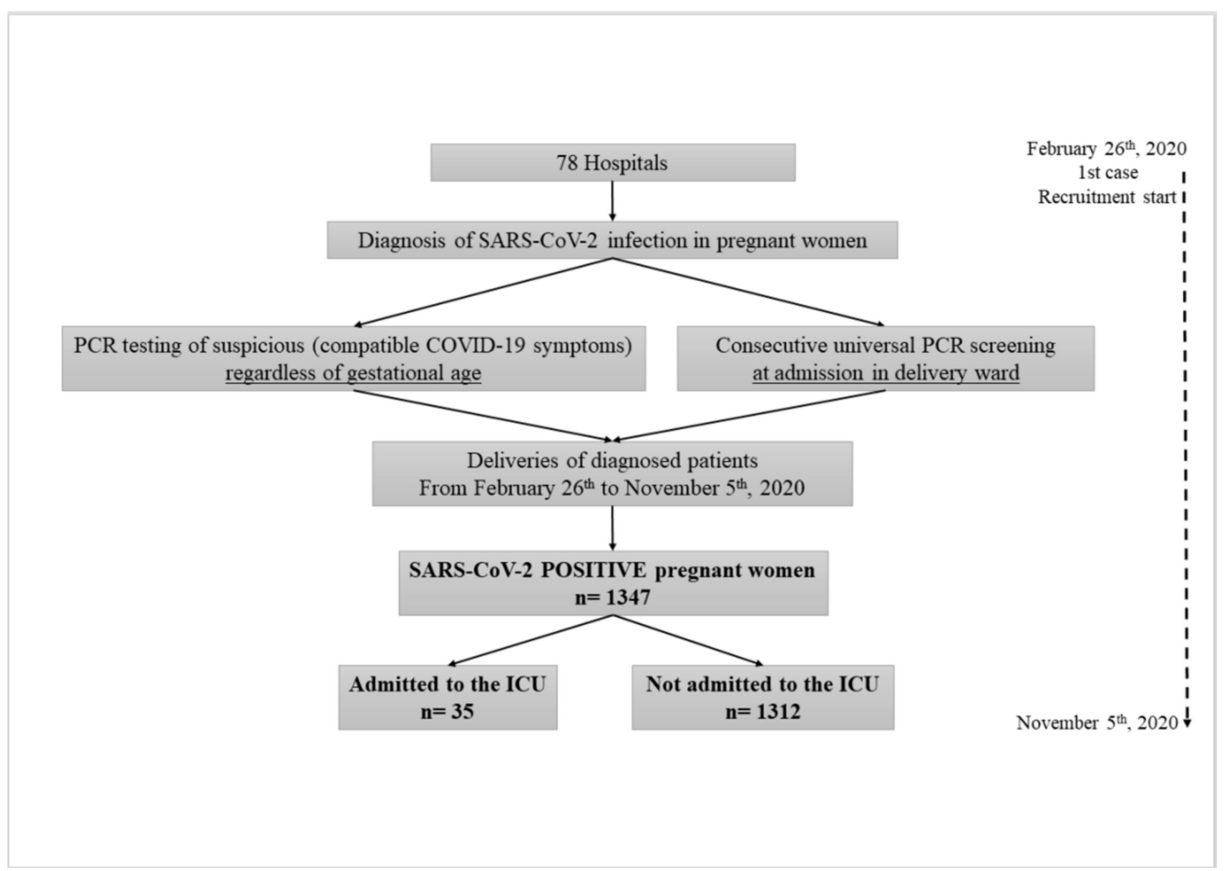

Figure 1. Flow chart of the study data.

The answers to the following questions allow us to describe the results of our study.

3.1. What Are the Characteristics of SARS-CoV-2 Infected Pregnant Women Admitted to the ICU?

Among our SARS-CoV-2 infected cohort, 51.1\% of the patients were asymptomatic, and $48.9 \%$ had COVID-19 symptoms (Table 1 ). The proportion of symptomatic patients increased up to $88.6 \%(31 / 35)$ in the ICU group compared to $47.9 \%$ among patients not admitted to the ICU $(p<0.001)$. Furthermore, $71 \%$ of symptomatic patients admitted in the ICU developed pneumonia (vs. $27.1 \%$ of symptomatic patients who did not need intensive care, $p<0.001$, Table 1). A lower gestational age at the diagnosis of SARS-CoV-2 infection was observed among ICU patients (median: 34 weeks +5 days, compared to 38 weeks +1 day in non-ICU patients, $p<0.001$ ) as well as a higher proportion of women who had required in vitro fertilization $(17.1 \%$ vs. $5.2 \%$ of non-ICU patients, $p=0.010)$ and a higher rate of multiple pregnancies $(11.4 \%$ vs. $1.6 \%$ of non-ICU patients, $p=0.003)$. We did not observe any other differences between groups in relation to maternal characteristics, comorbidities or current obstetric history.

\subsection{Does the Type of Delivery Influence the Risk of Icu Admission?}

We observed that the cesarean section was much more frequent in the ICU group $(88.6 \%$ vs. $26.1 \%, p<0.001)$, and its main reason was maternal respiratory worsening due to SARS-CoV-2 (51.4\% of cases). We found that $77.4 \%(24 / 31)$ of C-sections performed in ICU patients were carried out before their admission to this unit and $22.6 \%(7 / 31)$ after they were already receiving intensive care. 
Table 1. Demographic characteristics, comorbidities, current obstetric history, clinical presentation of SARS-CoV-2 infection and analytics of the study participants $(\mathrm{n}=1347)$.

\begin{tabular}{|c|c|c|c|c|}
\hline \multirow{2}{*}{ Number (\%) } & Total & Admitted ICU & No ICU & \multirow{2}{*}{$p$-Value } \\
\hline & 1347 & $35(2.6)$ & 1312 (97.4) & \\
\hline \multicolumn{5}{|l|}{ Maternal characteristics } \\
\hline Maternal age (years; median/IQR) & $33(28-37)$ & $33(26.5-38)$ & $33(28-37)$ & 0.623 \\
\hline Age Range 18-24 & $183 / 1336(13.7)$ & $5(14.3)$ & $178 / 1301(13.7)$ & \multirow{3}{*}{0.858} \\
\hline $25-34$ & $633 / 1336(47.4)$ & $15(42.9)$ & $618 / 1301(47.5)$ & \\
\hline $35-49$ & $520 / 1336(38.9)$ & $15(42.9)$ & $505 / 1301(38.8)$ & \\
\hline Ethnicity White European & $785 / 1344(58.4)$ & $17(48.6)$ & $768 / 1309(58.7)$ & \multirow{5}{*}{0.253} \\
\hline Latino Americans & $374 / 1344(27.8)$ & $13(37.1)$ & $361 / 1309(27.6)$ & \\
\hline Arab & $110 / 1344(8.2)$ & $5(14.3)$ & $105 / 1309(8.0)$ & \\
\hline Asian non-Hispanic & $40 / 1344(3.0)$ & $0(0.0)$ & $40 / 1309(3.1)$ & \\
\hline Black non-Hispanic & $35 / 1344(2.6)$ & $0(0.0)$ & $35 / 1309(2.7)$ & \\
\hline Ethnicity (2 categories) White & $785 / 1344(58.4)$ & $17(48.6)$ & $768 / 1309(58.7)$ & \multirow[b]{2}{*}{0.232} \\
\hline $\begin{array}{c}\text { European } \\
\text { Non-White European }\end{array}$ & $559 / 1344(41.6)$ & $18(51.4)$ & $541 / 1309(41.3)$ & \\
\hline Ethnicity (2 categories) Latino & $374 / 1344(27.8)$ & $13(37.1)$ & $361 / 1309(27.6)$ & \multirow[b]{2}{*}{0.213} \\
\hline $\begin{array}{c}\text { Americans } \\
\text { Non- Latino Americans }\end{array}$ & $970 / 1344(72.2)$ & $22(62.9)$ & $948 / 1309(72.4)$ & \\
\hline Blood group Type A & $544 / 1287(42.3)$ & $18 / 34(52.9)$ & $526 / 1253(42.0)$ & \multirow{4}{*}{$0.639^{a}$} \\
\hline Type O & $535 / 1287(41.6)$ & $12 / 34(35.3)$ & $523 / 1253(41.7)$ & \\
\hline Type B & $154 / 1287(12.0)$ & $3 / 34(8.8)$ & $151 / 1253(12.1)$ & \\
\hline Type AB & $54 / 1287(4.2)$ & $1 / 34(2.9)$ & $53 / 1253(4.2)$ & \\
\hline $\mathrm{Rh} \mathrm{Rh}+$ & $1146 / 1289(88.9)$ & $33 / 34(97.1)$ & $1113 / 1255(88.7)$ & \multirow{2}{*}{$0.167^{\mathrm{a}}$} \\
\hline $\mathrm{Rh}-$ & $143 / 1289(11.1)$ & $1 / 34(2.9)$ & $142 / 1255(11.3)$ & \\
\hline Nulliparous & $516(38.7)$ & $15(42.9)$ & $501(38.2)$ & 0.712 \\
\hline Smoking $b$ & $131 / 1290(10.2)$ & $1 / 33(3.0)$ & $130 / 1257(10.3)$ & 0.244 \\
\hline Maternal comorbidities & & & & \\
\hline Obesity $\left(\mathrm{BMI}>30 \mathrm{~kg} / \mathrm{m}^{2}\right)$ & $245(18.8)$ & $9(26.5)$ & $236(18.6)$ & 0.243 \\
\hline Cardiovascular comorbidities & $32(2.4)$ & $2(5.7)$ & $30(2.3)$ & 0.204 \\
\hline Pulmonary comorbidities & $53(3.9)$ & $3(8.6)$ & $50(3.8)$ & 0.169 \\
\hline Hematologic comorbidities & $48(3.6)$ & $2(5.7)$ & $46(3.5)$ & 0.513 \\
\hline Other comorbidities & $54(4.0)$ & $0(0.0)$ & $54(4.1)$ & 0.214 \\
\hline \multicolumn{5}{|l|}{ Current obstetric history } \\
\hline Multiple pregnancy & $25(1.9)$ & $4(11.4)$ & $21(1.6)$ & 0.003 \\
\hline In Vitro Fertilization & $74(5.5)$ & $6(17.1)$ & $68(5.2)$ & 0.010 \\
\hline Hemoglobin $<10 \mathrm{~g} / \mathrm{dL}$ & $60 / 1299(4.6)$ & $4 / 34(11.8)$ & $56 / 1265(4.4)$ & 0.068 \\
\hline Platelets $<100,000 / \mu \mathrm{L}$ & $12 / 1298(0.9)$ & $1(2.9)$ & $11 / 1263(0.9)$ & 0.281 \\
\hline Pregnancy-induced hypertension & $36 / 1308(2.8)$ & $3(8.6)$ & $33 / 1273(2.6)$ & 0.069 \\
\hline Gestational diabetes & $97 / 1309(7.4)$ & $2(5.7)$ & $95 / 1274(7.5)$ & 1.000 \\
\hline $\begin{array}{c}\text { Gestational age at diagnosis (weeks + } \\
\text { days; median/IQR) }\end{array}$ & $38+1(33+6-39+5)$ & $34+5(30+0-37+3)$ & $38+1(34+0-39+6)$ & $<0.001$ \\
\hline $\begin{array}{c}\text { Gestational age Range at diagnosis }< \\
13 \text { weeks (1st trimester) }\end{array}$ & $21(1.6)$ & $1(2.9)$ & $20(1.5)$ & \multirow{3}{*}{0.742} \\
\hline 13 to $<27$ weeks (2nd trimester) & $149(11.1)$ & $3(8.6)$ & & \\
\hline$\geq 27$ weeks (3rd trimester) & & & $146(11.1)$ & \\
\hline $\begin{array}{c}\text { Clinical presentation of SARS-CoV-2 } \\
\text { infection }\end{array}$ & $1177(87.4)$ & $31(88.6)$ & $1146(87.3)$ & \multirow[b]{3}{*}{$<0.001$} \\
\hline Asymptomatic & $688(51.1)$ & $4(11.4)$ & $684(52.1)$ & \\
\hline Symptomatic & $659(48.9)$ & $31(88.6)$ & $628(47.9)$ & \\
\hline \multicolumn{5}{|l|}{$\begin{array}{c}\text { Symptomatology among symptomatic } \\
\text { patients }\end{array}$} \\
\hline Mild-moderate symptoms & $467 / 659(70.9)$ & $9 / 31(29.0)$ & $458 / 628(72.9)$ & \multirow[t]{2}{*}{$<0.001$} \\
\hline $\begin{array}{l}\text { Fever (with or without other } \\
\text { symptoms) }\end{array}$ & $189 / 467(40.5)$ & $4 / 9(44.4)$ & $185 / 458(40.4)$ & \\
\hline Other symptoms (different from fever) & $278 / 467(59.5)$ & $5 / 9(55.6)$ & $273 / 458(59.6)$ & \\
\hline Pneumonia & $192 / 659(29.1)$ & $22 / 31(71.0)$ & $170 / 628(27.1)$ & $<0.001$ \\
\hline
\end{tabular}

a The interaction between blood group and Rh was analyzed by multivariable logistic regression modeling: the association of this interaction with ICU admission was not statistically significant. ${ }^{b}$ Current smokers + ex-smokers. 
Higher rates of prematurity were noticed among patients admitted to the ICU $(65.7 \%$ vs. $9.6 \%, p<0.001$, Table 2 ), with $91.3 \%$ being preterm deliveries in ICU patients iatrogenic and only $8.7 \%$ had a spontaneous onset.

Table 2. Perinatal characteristics and complications of the study participants $(n=1347)$.

\begin{tabular}{|c|c|c|c|c|}
\hline \multirow{2}{*}{ Number (\%) } & Total & Admitted ICU & No ICU & \multirow{2}{*}{$p$-Value } \\
\hline & 1347 & $35(2.6)$ & $1312(97.4)$ & \\
\hline \multicolumn{5}{|l|}{ Perinatal characteristics } \\
\hline $\begin{array}{c}\text { Gestational age at delivery (weeks + } \\
\text { days; median/IQR) }\end{array}$ & $39+3(38+2-40+3)$ & $35+2(32+0-38+0)$ & $39+3(38+3-40+3)$ & 0.001 \\
\hline $\begin{array}{c}\text { Gestational age Range at delivery }<28 \\
\text { weeks }\end{array}$ & $10(0.7)$ & $3(8.6)$ & $7(0.5)$ & \\
\hline 28 to $<32$ weeks & $21(1.6)$ & $6(17.1)$ & $15(1.1)$ & \multirow[t]{3}{*}{$<0.001$} \\
\hline 32 to $<37$ weeks & $118(8.8)$ & $14(40.0)$ & $104(7.9)$ & \\
\hline$\geq 37$ weeks & $1198(88.9)$ & $12(34.3)$ & $1186(90.4)$ & \\
\hline Type of delivery Eutocic & $832(61.8)$ & $3(8.6)$ & $829(63.2)$ & \\
\hline Instrumental & $142(10.5)$ & $1(2.9)$ & $141(10.7)$ & \multirow[t]{2}{*}{$<0.001$} \\
\hline Cesarean & $373(27.7)$ & $31(88.6)$ & $342(26.1)$ & \\
\hline Anestesia & $1141 / 1334(85.8)$ & $33 / 34(97.1)$ & $1108 / 1300(85.2)$ & \multirow[t]{4}{*}{0.049} \\
\hline General & $30 / 1131(2.7)$ & $12 / 33(36.4)$ & $18 / 1098(1.6)$ & \\
\hline Raquídea & $161 / 1131(14.2)$ & $11 / 33(33.3)$ & $150 / 1098(13.7)$ & \\
\hline Epidural & $886 / 1131(78.3)$ & $8 / 33(24.2)$ & $878 / 1098(80.0)$ & \\
\hline Local & $17 / 1131(1.5)$ & $0 / 33(0.0)$ & $17 / 1098(1.5)$ & \multirow[t]{2}{*}{$<0.001$} \\
\hline Combinada & $37 / 1131(3.3)$ & $2 / 33(6.1)$ & $35 / 1098(3.2)$ & \\
\hline $\begin{array}{c}\text { Preterm deliveries }(<37 \text { weeks } \\
\text { of gest age })\end{array}$ & $149(11.1)$ & $23(65.7)$ & $126(9.6)$ & $<0.001$ \\
\hline $\begin{array}{l}\text { Obstetrical complications. } \\
\text { Hemorrhagic events: }\end{array}$ & $70(5.2)$ & $7(20.0)$ & $63(4.8)$ & 0.002 \\
\hline Abruptio placentae & $12(0.9)$ & $3(8.6)$ & $9(0.7)$ & 0.003 \\
\hline Postpartum hemorrhage & $61(4.5)$ & $6(17.1)$ & $55(4.2)$ & 0.004 \\
\hline Hemorrhagic events at term & $54 / 70(77.1)$ & $3 / 7(42.9)$ & $51 / 63(81.0)$ & \\
\hline Hemorrhagic events preterm & $16 / 70(22.9)$ & $4 / 7(57.1)$ & $12 / 63(19.0)$ & 0.043 \\
\hline Pre-eclampsia: & $69(5.1)$ & $13(37.1)$ & $56(4.3)$ & $<0.001$ \\
\hline Moderate pre-eclampsia & $41(3.0)$ & $3(8.6)$ & $38(2.9)$ & 0.087 \\
\hline Severe pre-eclampsia & $28(2.1)$ & $10(28.6)$ & $18(1.4)$ & $<0.001$ \\
\hline Medical complications & & & & \\
\hline Thromboembolic events: & & & & \\
\hline Deep venous thrombosis & $7(0.5)$ & $2(5.7)$ & $5(0.4)$ & 0.013 \\
\hline Pulmonary embolism & $10(0.7)$ & $5(14.3)$ & $5(0.4)$ & $<0.001$ \\
\hline $\begin{array}{l}\text { Disseminated intravascular } \\
\text { coagulation }\end{array}$ & $4(0.3)$ & $3(8.6)$ & $1(0.1)$ & $<0.001$ \\
\hline Invasive ventilation & $14(1.0)$ & $14(40.0)$ & $0(0.0)$ & $<0.001$ \\
\hline Transfusion & $15 / 985(1.5)$ & $8 / 30(26.7)$ & $7 / 955(0.7)$ & $<0.001$ \\
\hline Maternal mortality & $2(0.1 \%)$ & $1(2.9)$ & $1(0.1)$ & 0.051 \\
\hline
\end{tabular}

\subsection{What Are the Main Causes of ICU Admission?}

We observed that only $11.4 \%$ of the ICU admissions were for purely obstetric reasons (two cases of postpartum hemorrhages and two of severe pre-eclampsia/eclampsia in asymptomatic patients), while $40 \%$ were due to non-obstetric causes (worsening of the maternal condition and respiratory failure due to SARS-CoV-2 pneumonia) (Table 3). Additionally, 31.4\% of ICU admission can be attributed to a combination of COVID-19 symptoms and obstetrical complications (pre-eclampsia and/or postpartum hemorrhages), and the remaining $8.6 \%$ due to a combination of COVID-19 symptoms and pulmonary embolism (PE) (medical complication) (Table 3). 
Table 3. Main causes of ICU admission.

\begin{tabular}{|c|c|c|c|}
\hline & Asymptomatic & $\begin{array}{l}\text { COVID-19 } \\
\text { Mild-Moderate } \\
\text { Symptoms }\end{array}$ & Pneumonia \\
\hline $\begin{array}{c}\text { No obstetrical complication } \\
\text { Obstetrical complications }\end{array}$ & & & $14(40.0)$ \\
\hline Pre-eclampsia/eclampsia & $2(5.7)$ & $4(11.4)$ & $2(5.7)$ \\
\hline Postpartum hemorrhage & $2(5.7)$ & $1(2.9)$ & $2(5.7)$ \\
\hline $\begin{array}{l}\text { Pre-eclampsia + Postpartum } \\
\text { hemorrhage }\end{array}$ & & & $2(5.7)$ \\
\hline $\begin{array}{c}\text { Medical complications } \\
\text { Pulmonary embolism } \\
\text { Others }\end{array}$ & $2(5.7)^{a}$ & $\begin{array}{l}1(2.9) \\
1(2.9)^{b}\end{array}$ & $2(5.7)$ \\
\hline
\end{tabular}

3.4. Is there an Influence of Obstetrical Conditions on the Risk of ICU Admission? What Are the Most Common Maternal Complications?

The proportion of women who developed pre-eclampsia was significantly higher in the group of patients admitted in the UCI (37.1\% vs. $4.3 \%, p<0.001$, Table 2$) ; 76.9 \%(10 / 13)$ of pre-eclampsia cases among ICU patients were severe (including two cases of HELLP and one case of eclampsia).

On the other hand, the odds of hemorrhagic events (postpartum hemorrhages and/or abruptio placentae) among ICU patients was nearly five times higher than in non-ICU patients (20.0\% vs. $4.8 \%, p=0.002$, Table 2$)$; therefore, an increased rate of transfusions was also observed in the ICU group $(26.7 \%$ vs. $0.7 \%$ in the non-ICU group, $p<0.001$, Table 2$)$.

However, the multivariable analysis results from the estimated models showed that pre-eclampsia, as well as hemorrhagic events by themselves, were not a risk factor for ICU admission in SARS-CoV-2 infected pregnant women, but when they coexist with pneumonia, the aOR of requiring intensive care rises to $800.0\left(95 \%\right.$ CI $\left.125.7-1.0 \times 10^{10}\right)$ and to $106.2\left(95 \%\right.$ CI $\left.17.4-7.7 \times 10^{8}\right)$, respectively (Table 4$)$. In addition, as observed in both multivariable models, the presence of pneumonia by itself also represents an important risk factor for intensive care requirements (Table 4).

The incidence of thromboembolic events was also significantly higher in the group of patients admitted in the ICU (Table 2), having been affected the 5.7\%, 14.3\% and 8.6\% of these patients by deep venous thrombosis, pulmonary embolism and disseminated intravascular coagulation, respectively, even when treated with LMWH at prophylactic doses.

\subsection{Maternal Mortality, Stillbirth and Neonatal Outcomes}

Maternal mortality in the entire series was $0.14 \%(n=2)$, both cases associated with Disseminated Intravascular Coagulation (DIC) (mortality associated with DIC $=2 / 4=50 \%$ ). The first patient died in the operating room because of massive postpartum hemorrhages after abruptio placentae associated with DIC. The second patient died after several days in the ICU due to severe pneumonia with acute respiratory distress syndrome associated with septic shock and the development of DIC, which led to a massive bilateral PE and cardiac arrest.

The incidence of stillbirth and neonatal outcomes are recorded in Table 2. 
Table 4. Multivariable analysis of ICU admission risk.

\begin{tabular}{|c|c|c|c|c|}
\hline Initial Maximum Model & $\begin{array}{c}\text { Final Estimative } \\
\text { Model }\end{array}$ & $\begin{array}{l}\text { Variables Associated } \\
\text { with ICU Admission }\end{array}$ & $p$-Value & OR $(95 \% \mathrm{CI})$ \\
\hline \multirow{5}{*}{$\begin{array}{l}\text { ICU admission }= \\
\text { interaction (Pre-eclampsia } \\
\text { and COVID-19 symptoms) } \\
+ \text { maternal age }+ \text { multiple } \\
\text { pregnancy }\end{array}$} & \multirow{5}{*}{$\begin{array}{c}\text { ICU admission = } \\
\text { interaction } \\
\text { (Pre-eclampsia and } \\
\text { COVID-19 symptoms) }\end{array}$} & $\begin{array}{l}\text { Mild-moderate } \\
\text { symptoms without } \\
\text { pre-eclampsia }\end{array}$ & $N S^{\text {a }}$ & \\
\hline & & $\begin{array}{c}\text { Pneumonia without } \\
\text { pre-eclampsia }\end{array}$ & $<0.001^{\mathrm{a}}$ & $30.3\left(7.6-2.5 \times 10^{8}\right)$ \\
\hline & & $\begin{array}{c}\text { Asymptomatic with } \\
\text { pre-eclampsia }\end{array}$ & $N S^{\mathrm{a}}$ & \\
\hline & & $\begin{array}{l}\text { Mild-moderate } \\
\text { symptoms with } \\
\text { pre-eclampsia }\end{array}$ & $N S^{\text {a }}$ & \\
\hline & & $\begin{array}{l}\text { Pneumonia with } \\
\text { pre-eclampsia }\end{array}$ & $<0.001^{a}$ & $800.0\left(125.7-1.0 \times 10^{10}\right)$ \\
\hline \multirow{5}{*}{$\begin{array}{c}\text { ICU admission = } \\
\text { interaction (Hemorrhagic } \\
\text { events and COVID-19 } \\
\text { symptoms) + maternal age } \\
+ \text { multiple pregnancy }\end{array}$} & \multirow{5}{*}{$\begin{array}{c}\text { ICU admission = } \\
\text { interaction } \\
\text { (Hemorrhagic events } \\
\text { and COVID-19 } \\
\text { symptoms) }\end{array}$} & $\begin{array}{c}\text { Mild-moderate } \\
\text { symptoms without } \\
\text { hemorrhagic events }\end{array}$ & $N S^{b}$ & \\
\hline & & $\begin{array}{l}\text { Pneumonia without } \\
\text { hemorrhagic events }\end{array}$ & $<0.001^{b}$ & $24.4\left(8.4-2.2 \times 10^{8}\right)$ \\
\hline & & $\begin{array}{l}\text { Asymptomatic with } \\
\text { hemorrhagic events }\end{array}$ & $N S^{b}$ & \\
\hline & & $\begin{array}{l}\text { Mild-moderate } \\
\text { symptoms with } \\
\text { hemorrhagic events }\end{array}$ & $N S^{b}$ & \\
\hline & & $\begin{array}{c}\text { Pneumonia with } \\
\text { hemorrhagic events }\end{array}$ & $<0.001^{b}$ & $106.2\left(17.4-7.7 \times 10^{8}\right)$ \\
\hline
\end{tabular}

Pre-eclampsia: moderate + severe. COVID-19 symptoms: 3 categories = asymptomatic, mild-moderate symptoms and pneumonia. Maternal age: tested as numerical and categorical ( 3 categories, Table 1) variable in two alternative models. ${ }^{\text {a }}$ Compared to basal category $=$ asymptomatic without pre-eclampsia. Hemorrhagic events: Abruptio placentae + postpartum hemorrhage. ${ }^{b}$ Compared to basal category $=$ asymptomatic without hemorrhagic events.

\section{Discussion}

To our knowledge, this is one of the first studies targeting ICU admission factors of SARS-CoV-2 infected mothers. The main strength of the study is the large cohort of SARS-CoV-2 positive deliveries (1347 from 78 centers across Spain) and the considerable quantity of ICU admissions (35) included.

The incidence of admission to the ICU in this series was $2.6 \%$, lower than the one reported by previous studies $[2,12]$. This difference may be related to the PCR universal screening (regardless of mother's symptomatology), established in the participating hospitals and also to the existence of a universal public health care system in our country, which means that every woman, regardless of their socio-economic circumstances, receive the same medical care and follow-up of pregnancy and that patients can consult and be assessed before a severe disease is developed. Finally, the long period of data collection may have resulted in better knowledge of the disease and, consequently, a decrease in the rate of ICU admissions in the second and following waves of the pandemic.

No differences in maternal characteristics or comorbidities were observed between ICU and non-ICU patients, except for IVF and multiple pregnancies (higher rates among ICU). Prior to the COVID-19 pandemic, these conditions had already been described as risk factors for obstetric morbidity and, therefore, for ICU admission, due to a higher presence of comorbidities (hypertension, thrombophilia, etc.) and complications among IVF mothers [13-16] and multiple pregnancies [17]. In a study carried out in SARS-CoV-2 infected pregnant women, a higher risk of ICU admission (due to pre-eclampsia) was reported in 
IVF mothers [18], as hypertension is a risk factor of a worse COVID-19 prognosis [19] and a synergistic effect of COVID-19 and pre-eclampsia cannot be ruled out nor a COVID-19 induced pre-eclampsia-like syndrome [20,21].

The high incidence of C-sections and preterm deliveries (mostly iatrogenic) that was observed in the ICU group could be explained by the urgency to terminate the pregnancy due to a worsening of the mother's condition and respiratory failure, which was the most frequent complication described in ICU patients. We must always bear in mind that maternal oxygen consumption increases $20 \%$ during pregnancy owing to increased metabolic demands, and this, combined with a reduced functional residual pulmonary capacity, result in rapid desaturation during respiratory compromise [22]. In one of our first publications [23] with a small sample size, it was found that C-sections could be a risk factor for ICU admission; however, our new data suggest that this type of delivery might be a consequence of mother worsening, and not a risk factor.

In our SARS-CoV-2 infected cohort, the main risk factor for ICU admission is the development of pneumonia. On the other hand, when pneumonia coexists with preeclampsia, the risk of requiring intensive care increases exponentially. Although SARS-CoV2 infection primarily affects the respiratory system, its systemic manifestations, such as hypertension, renal disease, thrombocytopenia and liver damage, are also found and easily confused with pre-eclampsia [24]. An increased incidence of severe pre-eclampsia has been observed in pregnant women with SARS-CoV-2 compared to non-infected [25]. However, it must be noted that the analytical signs (inflammatory, hypertensive and biochemical alterations) of COVID-19 could be interpreted as alterations due to pre-eclampsia instead and, to correctly classify these cases (and distinguish between moderate and severe preeclampsia), it would be necessary to measure angiogenic factors in the blood (sFlt-1/PlGF) and perform an echo-Doppler of the uterine arteries [21].

The incidence of hemorrhagic events in our entire series was 5.2\% but increased up to $20 \%$ in those who required admission to the ICU. In previous studies, there was controversy over whether SARS-CoV-2 infection is a risk factor for postpartum hemorrhage [2,25-27]. In our study, hemorrhagic events by themselves, or associated with COVID-19 mild-moderate symptoms, did not increase the risk of ICU admission; however, when this obstetric complication coexisted with pneumonia, the risk of requiring intensive care was especially high. Therefore, we should closely monitor blood loss and analytical alterations of women with severe pneumonia to provide early management. Additionally, it would be interesting to conduct studies that analyze this association and the presence of risk factors in these women for developing hemorrhagic events.

Another consideration is the high rates of PE $(0.7 \%$, despite even prophylactic heparin in the SARS-CoV-2 infected cohort, which is higher than the ratios reported prior to the COVID-19 pandemic (1.72 cases per 1.000 deliveries for PE and 0.3 to 3.5 cases per 1.000 deliveries for DIC) [28,29]. This high incidence of thromboembolic events (and, especially high in ICU patients) could be explained by the excessive inflammation produced by cytokine release (involved in abnormal activation of coagulation pathways and inhibition of anticoagulant vias), the increase of the vasoconstrictor angiotensin II (due to angiotensin-converting enzyme two downregulation) and the immobilization of patients in the ICU [30,31]. Mortality in patients who develop DIC is $50 \%$, like DIC's mortality associated with sepsis of obstetric origin (50-80\%) [29].

Therefore, surveillance and rapid intervention should be intensified in SARS-CoV-2 infected pregnant women with the mentioned risk factors and complications. Similarly, emphasis should be placed on anticoagulant therapy in these patients due to the increased thromboembolic risk, C-section surgery and immobilization in the ICU.

As a limitation of this study, it should be highlighted that symptomatic patients are over-represented in our study population since not all participating hospitals had a universal antenatal screening program for SARS-CoV-2 infection (so only identified symptomatic cases) or implemented the program later. Another limitation is related to the identification and classification of pre-eclampsia cases, as angiogenic markers and 
echo-Doppler of the uterine arteries were not performed in most of the patients since this is not a common practice in many hospitals.

Moreover, the small number of ICU admissions $(n=35)$ may have penalized the power of analyses, proven by the wide OR's confidence intervals obtained in the multivariable analyses, which should be interpreted cautiously.

Finally, it should be mentioned that most ICU admissions registered in this cohort took place during the first wave of the pandemic when COVID-19 was unknown, and there were no homogeneous protocols/ICU admission criteria for these patients. Furthermore, the existence of Respiratory Intermediate Care Units in some participating hospitals (depending on the healthcare level of the center) could have led to an underestimation of the number of critical patients, as there were patients about to be admitted to the ICU but who were attended in these units. Additionally, the criteria for classifying the disease as mild, moderate or severe were not correctly implemented, and the specific medical treatment for COVID-19 was also very variable, depending on the protocols of each hospital and the moment of the pandemic, since they were frequently modified based on the emergent literature. Patients hospitalized for COVID-19 were treated with different drugs (corticosteroids, lopinavir/ritonavir, azithromycin, hydroxychloroquine, interferon beta1, tocilizumab and prophylactic or therapeutic heparin), and asymptomatic or symptomatic patients without hospitalization could receive or not prophylactic heparin.

\section{Conclusions}

Respiratory failure due to SARS-CoV-2 pneumonia is the main cause of ICU admission among SARS-CoV-2 infected pregnant women. Multiple pregnancy or/and in vitro fertilization are risk factors for ICU admission, as well as pre-eclampsia and hemorrhagic events when they coexist with pneumonia. The higher incidence of C-sections and preterm deliveries among ICU patients are explained by the need to terminate the pregnancy due to a worsening of the mother's condition.

Supplementary Materials: The following supporting information can be downloaded at: https: / / www.mdpi.com/article/10.3390/biomedicines10020475/s1, Table S1: List of hospitals members of the Spanish Obstetric Emergency Group included in this study $(n=78)$; Table S2: STROBE Statement-checklist of items that should be included in reports of observational studies.

Author Contributions: Conceptualization, O.M.P.; methodology, A.Á.B., N.A.A.K., M.L.d.l.C.C. and O.M.P.; software, M.L.d.l.C.C.; validation, A.Á.B., N.A.A.K., S.C.M., M.L.d.l.C.C., L.F.A., A.A.S., P.P.R., A.M.V., L.C.G., J.G.F. and O.M.P.; formal analysis, M.L.d.l.C.C.; investigation, A.Á.B., N.A.A.K., S.C.M., M.L.d.l.C.C., L.F.A., A.A.S., P.P.R., A.M.V., L.C.G., J.G.F. and O.M.P.; resources, O.M.P.; data curation, M.L.d.l.C.C.; writing—original draft preparation, A.Á.B., N.A.A.K., S.C.M., M.L.d.l.C.C. and O.M.P.; writing - review and editing, A.Á.B. and S.C.M.; visualization, A.Á.B., N.A.A.K., S.C.M., M.L.d.I.C.C., L.F.A., A.A.S., P.P.R., A.M.V., L.C.G., J.G.F. and O.M.P.; supervision, J.G.F. and O.M.P.; project administration, O.M.P.; funding acquisition, O.M.P. All authors have read and agreed to the published version of the manuscript.

Funding: This research was supported by public funds obtained in competitive calls: Grant COV20/00021 from the Instituto de Salud Carlos III—Spanish Ministry of Health and co-financed with Fondo Europeo de Desarrollo Regional (FEDER) funds.

Institutional Review Board Statement: The study was conducted according to the guidelines of the Declaration of Helsinki and approved by the Institutional Review Board (or Ethics Committee) of Puerta de Hierro University Hospital (PE 55/20; 23 March 2020).

Informed Consent Statement: Informed consent was obtained from all subjects that were involved in the study.

Data Availability Statement: The data presented in this study are available on request from the corresponding author. The data are not publicly available due to the multicenter nature of the study.

Acknowledgments: Assistance with the article: Spanish Obstetric Emergency Group (S.O.E.G.): María Belén Garrido Luque (Hospital Axarquia), Camino Fernández Fernández (Complejo Asistencial de 
León), Ana Villalba Yarza (Complejo Asistencial Universitario de Salamanca), Esther María Canedo Carballeira (Complexo Hospitalario Universitario A Coruña), María Begoña Dueñas Carazo (Hospital Clínico Universitario de Santiago de Compostela), Rosario Redondo Aguilar (Complejo Hospitalario Jaén), Esther Álvarez Silvares (Complejo Hospitalario Universitario de Ourense), María Isabel Pardo Pumar (Complejo Hospitalario Universitario de Pontevedra), Macarena Alférez Álvarez-Mallo (HM Hospitales), Víctor Muñoz Carmona (Hospital Alto Guadalquivir, Andújar), Noelia Pérez Pérez (Hospital Clínico San Carlos), Cristina Álvarez Colomo (Hospital Clínico Universitario de Valladolid), Onofre Alomar Mateu (Hospital Comarcal d'Inca), Claudio Marañon Di Leo (Hospital Costa del Sol), María del Carmen Parada Millán (Hospital da Barbanza), Adrián Martín García (Hospital de Burgos), José Navarrina Martínez (Hospital de Donostia), Anna Mundó Fornell (Hospital Universitario Santa Creu i Sant Pau), Elena Pascual Salvador (Hospital deMinas de Riotinto), Tania Manrique Gómez (Hospital de Montilla y Quirón Salud Córdoba), Marta Ruth Meca Casbas (Hospital de Poniente), Noemí Freixas Grimalt (Hospital Universitari Son Llàtzer), Adriana Aquise and María del Mar Gil (Hospital de Torrejón), Eduardo Cazorla Amorós (Hospital de Torrevieja), Alberto Armijo Sánchez (Hospital de Valme), María Isabel Conca Rodero (Hospital de Vinalopó), Ana Belén Oreja Cuesta (Hospital del Tajo), Cristina Ruiz Aguilar (Hospital Doctor Peset, Valencia), Susana Fernández García (Hospital General de L'Hospitalet), Carmen Baena Luque (Hospital Infanta Margarita de Cabra), Luz María Jiménez Losa (Hospital Infanta Sofía), Susana Soldevilla Pérez (Hospital Jerez de la Frontera), María Reyes Granell Escobar (Hospital Juan Ramón Jiménez), Manuel Domínguez González (Hospital La Línea), Flora Navarro Blaya (Hospital Universitario Rafael Méndez), Juan Carlos Wizner de Alva (Hospital San Pedro de Alcántara), Rosa Pedró Carulla (Hospital Sant Joan de Reus), Encarnación Carmona Sánchez (Hospital Santa Ana. Motril), Judit Canet Rodríguez (Hospital Santa Caterina de Salt), Eva Morán Antolín (Hospital Son Espases), Montse Macià (Hospital Universitari Arnau de Vilanova), Laia Pratcorona (Hospital Universitari Germans Trias i Pujol), Irene Gastaca Abásolo (Hospital Universitario Araba), Begoña Martínez Borde (Hospital Universitario de Bilbao), Óscar Vaquerizo Ruiz (Hospital Universitario de Cabueñes), José Ruiz Aragón (Hospital Universitario de Ceuta), Raquel González Seoane (Hospital Universitario de Ferrol), María Teulón González (Hospital Universitario de Fuenlabrada), Lourdes Martín González (Hospital Joan XXIII de Tarragona), Cristina Lesmes Heredia (Hospital Universitario Parc Taulí de Sabadell), Rut Bernardo (Hospital Universitario Río Hortega), Otilia González Vanegas (Hospital Universitario San Cecilio, Instituto de Investigación Biosanitaria, Granada), Lucía Díaz Meca (Hospital Universitario Virgen de la Arrixaca, Murcia), Alberto Puerta Prieto (Hospital Universitario Virgen de las Nieves, Instituto de Investigación Biosanitaria, Granada), María del Pilar Guadix Martín (Hospital Universitario Virgen Macarena), Carmen María Orizales Lago (Hospital Universitario Severo Ochoa, Leganés), José Antonio Sainz Bueno (Hospital Viamed, Grupo Chacón), Mónica Catalina Coello (Hospital Virgen Concha de Zamora), María José Núñez Valera (Hospital Virgen de la Luz), José Adanez García (Hospital Universitario Central de Asturias), Elena Ferriols-Pérez (Hospital del Mar), Marta Roqueta (Hospital Universitario Josep Trueta), Marta García Sánchez (Hospital Universitario Quirónsalud de Málaga), Emilio Couceiro Naveira (Hospital Álvaro Cunqueiro de Vigo), Mar Muñoz Chapuli (Hospital Universitario Gregorio Marañón), Elena Pintado Paredes (Hospital Universitario de Getafe), Inmaculada Mejía Jiménez (Hospital Universitario 12 de Octubre), Laura González Rodríguez (Hospital Álvaro Cunqueiro), Celia Cuenca Marín (Hospital regional de Málaga), Ana Belén Oreja Cuesta (Hospital del Tajo), Pilar Prats Rodríguez (Hospital Universitario QuirónSalud Dexeus), Irene Fernández Buhigas (Hospital Universitario de Torrejón), María Victoria Rodríguez Gallego (Complejo Hospitalario San Millán-San Pedro), Ana María Fernández Alonso (Hospital Universitario Torrecárdenas), Rocío López Pérez (Hospital Universitario Santa Lucía), José Román Broullón Molanes (Hospital Universitario Puerta del Mar), María Begoña Encinas Pardilla (Hospital Universitario Puerta de Hierro de Majadahonda), Mercedes Ramírez Gómez (Hospital General La Mancha Centro), María Joaquina Gimeno Gimeno (Hospital Universitario Reina Sofía), Antonio Sánchez Muñoz (Hospital Universitario de Ciudad Real).

Conflicts of Interest: The authors declare no conflict of interest. 


\section{References}

1. Google. Coronavirus (COVID-19) Google News. 2021. Available online: https://news.google.com/covid19/map?hl=es\&mid= $\% 2 \mathrm{Fm} \% 2 \mathrm{~F} 02 \mathrm{j} 71 \&$ state $=5$ (accessed on 5 June 2021).

2. Allotey, J.; Stallings, E.; Bonet, M.; Yap, M.; Chatterjee, S.; Kew, T.; Debenham, L.; Llavall, A.C.; Dixit, A.; Zhou, D.; et al. Clinical manifestations, risk factors, and maternal and perinatal outcomes of coronavirus disease 2019 in pregnancy: Living systematic review and meta-analysis. BMJ 2020, 370, m3320. [CrossRef] [PubMed]

3. Bobrowski, R.A. Pulmonary physiology in pregnancy. Clin. Obstet. Gynecol. 2010, 53, 285-300. [CrossRef] [PubMed]

4. Brandt, J.S.; Hill, J.; Reddy, A.; Schuster, M.; Patrick, H.S.; Rosen, T.; Sauer, M.V.; Boyle, C.; Ananth, C.V. Epidemiology of coronavirus disease 2019 in pregnancy: Risk factors and associations with adverse maternal and neonatal outcomes. Am. J. Obstet. Gynecol. 2021, 224, 389.e1-389.e9. [CrossRef] [PubMed]

5. Collin, J.; Byström, E.; Carnahan, A.; Ahrne, M. Public Health Agency of Sweden's Brief Report: Pregnant and postpartum women with severe acute respiratory syndrome coronavirus 2 infection in intensive care in Sweden. Acta Obstet. Gynecol. Scand. 2020, 99, 819-822. [CrossRef] [PubMed]

6. $\quad$ Ellington, S.; Strid, P.; Tong, V.T.; Woodworth, K.; Galang, R.R.; Zambrano, L.D.; Nahabedian, J.; Anderson, K.; Gilboa, S.M. Characteristics of Women of Reproductive Age with Laboratory-Confirmed SARS-CoV-2 Infection by Pregnancy Status-United States, January 22-June 7, 2020. MMWR Morb. Mortal. Wkly Rep. 2020, 69, 769-775. [CrossRef]

7. Encinas, M.B.; Caño, A.; Marcos, B.; Sanz, A.; Rodríguez de la Torre, I.; Hernando, P; Fernández, A; Martínez, O. Registro español de cribado de Covid-19 en gestantes asintomáticas. Rev. Española Salud Públ. 2020, 94, 18.

8. Von Elm, E.; Altman, D.G.; Egger, M.; Pocock, S.J.; Gøtzsche, P.C.; Vandenbroucke, J.P. The Strengthening the Reporting of Observational Studies in Epidemiology (STROBE) statement: Guidelines for reporting observational studies. J. Clin. Epidemiol. 2008, 61, 344-349. [CrossRef]

9. $\quad$ Brown, M.A.; Magee, L.A.; Kenny, L.C.; Karumanchi, S.A.; McCarthy, F.P.; Saito, S.; Hall, D.R.; Warren, C.E.; Adoyi, G.; Ishaku, S. Hypertensive Disorders of Pregnancy. Hypertension 2018, 72, 24-43. [CrossRef]

10. Peduzzi, P.; Concato, J.; Kemper, E.; Holford, T.R.; Feinstein, A.R. A simulation study of the number of events per variable in logistic regression analysis. J. Clin. Epidemiol. 1996, 49, 1373-1379. [CrossRef]

11. Bates, D.; Mächler, M.; Bolker, B.; Walker, S. Fitting Linear Mixed-Effects Models Using lme4. J. Stat. Softw. 2015, 67, 1-48. [CrossRef]

12. Takemoto, M.L.; Menezes, M.D.O.; Andreucci, C.B.; Knobel, R.; Sousa, L.; Katz, L.; Fonseca, E.B.; Nakamura-Pereira, M.; Magalhães, C.G.; Diniz, C.S. Clinical characteristics and risk factors for mortality in obstetric patients with severe COVID-19 in Brazil: A surveillance database analysis. BJOG 2020, 127, 1618-1626. [CrossRef]

13. Woo, I.; Hindoyan, R.; Landay, M.; Ho, J.; Ingles, S.A.; McGinnis, L.K.; Paulson, R.J.; Chung, K. Perinatal outcomes after natural conception versus in vitro fertilization (IVF) in gestational surrogates: A model to evaluate IVF treatment versus maternal effects. Fertil. Steril. 2017, 108, 993-998. [CrossRef]

14. Allen, V.M.; Wilson, R.D.; Cheung, A. Pregnancy outcomes after assisted reproductive technology. J. Obstet. Gynaecol. Can. 2006, 28, 220-233. [CrossRef]

15. American College of Obstetricians and Gynecologists; Committee on Obstetric Practice; Committee on Genetics U.S. Food and Drug Administration. Committee Opinion No 671: Perinatal Risks Associated With Assisted Reproductive Technology. Obstet. Gynecol. 2016, 128, e61-e68. [CrossRef]

16. Pandey, S.; Shetty, A.; Hamilton, M.; Bhattacharya, S.; Maheshwari, A. Obstetric and perinatal outcomes in singleton pregnancies resulting from IVF/ICSI: A systematic review and meta-analysis. Hum. Reprod. Update 2012, 18, 485-503. [CrossRef] [PubMed]

17. Santana, D.S.; Surita, F.G.; Cecatti, J.G. Multiple Pregnancy: Epidemiology and Association with Maternal and Perinatal Morbidity. Rev. Bras. Ginecol. Obstet. 2018, 40, 554-562. [CrossRef]

18. Calvo, V.E.; Melguizo, S.C.; Abascal-Saiz, A.; Acebal, L.F.; Sánchez-Migallón, A.; Recarte, P.P.; Marín, C.C.; Puig, B.M.; Fernández, P.G.D.B.; Velasco, O.N.; et al. Perinatal outcomes of pregnancies resulting from assisted reproduction technology in SARS-CoV-2infected women: A prospective observational study. Fertil. Steril. 2021, 116, 731-740. [CrossRef] [PubMed]

19. Huang, S.; Wang, J.; Liu, F.; Liu, J.; Cao, G.; Yang, C.; Liu, W.; Tu, C.; Zhu, M.; Xiong, B. COVID-19 patients with hypertension have more severe disease: A multicenter retrospective observational study. Hypertens. Res. 2020, 43, 824-831. [CrossRef] [PubMed]

20. Coronado-Arroyo, J.C.; Concepción-Zavaleta, M.J.; Zavaleta-Gutiérrez, F.E.; Concepción-Urteaga, L.A. Is COVID-19 a risk factor for severe preeclampsia? Hospital experience in a developing country. Eur. J. Obstet. Gynecol. Reprod. Biol. 2021, 256, 502-503. [CrossRef]

21. Mendoza, M.; Garcia-Ruiz, I.; Maiz, N.; Rodo, C.; Garcia-Manau, P.; Serrano, B.; Lopez-Martinez, R.M.; Balcells, J.; FernandezHidalgo, N.; Carreras, E.; et al. Pre-eclampsia-like syndrome induced by severe COVID-19: A prospective observational study. BJOG 2020, 127, 1374-1380. [CrossRef]

22. Wise, R.A.; Polito, A.J.; Krishnan, V. Respiratory physiologic changes in pregnancy. Immunol. Allergy Clin. N. Am. 2006, 26, 1-12. [CrossRef] [PubMed]

23. Martínez-Perez, O.; Vouga, M.; Melguizo, S.C.; Acebal, L.F.; Panchaud, A.; Muñoz-Chápuli, M.; Baud, D. Association Between Mode of Delivery among Pregnant Women with COVID-19 and Maternal and Neonatal Outcomes in Spain. JAMA 2020, 324, 296-299. [CrossRef] [PubMed] 
24. Curiel-Balsera, E.; Prieto-Palomino, M.Á.; Muñoz-Bono, J.; Ruiz de Elvira, M.J.; Galeas, J.L.; Quesada García, G. Análisis de la morbimortalidad materna de las pacientes con preeclampsia grave, eclampsia y síndrome HELLP que ingresan en una Unidad de Cuidados Intensivos gineco-obstétrica. Med. Intensiv. 2011, 35, 478-483. [CrossRef]

25. Cruz Melguizo, S.; de la Cruz Conty, M.L.; Carmona Payán, P.; Abascal-Saiz, A.; Pintando Recarte, P.; González Rodríguez, L.; Cuenca Marín, C.; Martínez Varea, A.; Oreja Cuesta, A.B.; Rodríguez, P.P.; et al. Pregnancy Outcomes and SARS-CoV-2 Infection: The Spanish Obstetric Emergency Group Study. Viruses 2021, 13, 853. [CrossRef] [PubMed]

26. Hcini, N.; Maamri, F.; Picone, O.; Carod, J.F.; Lambert, V.; Mathieu, M.; Carles, G.; Pomar, L. Maternal, fetal and neonatal outcomes of large series of SARS-CoV-2 positive pregnancies in peripartum period: A single-center prospective comparative study. Eur. J. Obstet. Gynecol. Reprod. Biol. 2021, 257, 11-18. [CrossRef] [PubMed]

27. Wang, M.J.; Schapero, M.; Iverson, R.; Yarrington, C.D. Obstetric Hemorrhage Risk Associated with Novel COVID-19 Diagnosis from a Single-Institution Cohort in the United States. Am. J. Perinatol. 2020, 37, 1411-1416. [CrossRef]

28. Van Der Pol, L.M.; Tromeur, C.; Bistervels, I.M.; Ainle, F.N.; Van Bemmel, T.; Bertoletti, L.; Couturaud, F.; van Dooren, Y.P.; Elias, A.; Faber, L.M.; et al. Pregnancy-Adapted YEARS Algorithm for Diagnosis of Suspected Pulmonary Embolism. N. Engl. J. Med. 2019, 380, 1139-1149. [CrossRef]

29. Erez, O.; Mastrolia, S.A.; Thachil, J. Disseminated intravascular coagulation in pregnancy: Insights in pathophysiology, diagnosis and management. Am. J. Obstet. Gynecol. 2015, 213, 452-463. [CrossRef] [PubMed]

30. Klok, F.A.; Kruip, M.J.H.A.; Van der Meer, N.J.M.; Arbous, M.S.; Gommers, D.A.M.P.J.; Kant, K.M.; Kaptein, F.H.J.; van Paassen, J.; Stals, M.A.M.; Huisman, M.V.; et al. Incidence of thrombotic complications in critically ill ICU patients with COVID-19. Thromb. Res. 2020, 191, 145-147. [CrossRef] [PubMed]

31. Miesbach, W.; Makris, M. COVID-19: Coagulopathy, Risk of Thrombosis, and the Rationale for Anticoagulation. Clin. Appl. Thromb. Hemost. 2020, 26, 1-7. [CrossRef] 